\title{
THE EFFECT OF PINEAL EXTRACTS ON HORMONE-INDUCED RAT UTERINE CONTRACTILITY
}

\author{
R. H. DAVIS \\ Departments of Obstetrics and Gynecology and Physiology and Biophysics, \\ Hahnemann Medical College and Hospital, Philadelphia, \\ Pennsylvania 19102, U.S.A.
}

(Received 30th December 1970)

Crude pineal extracts are apparently capable of exerting both a stimulatory and an inhibitory effect on the reproductive system of laboratory animals. The two active influences were separated as far as possible by means of TCA extraction (Reiss, Davis, Sideman, Mauer \& Plichta, 1963) and the general methods of preparing the various cattle pineal fractions, used in the present study, were described. The inhibitory activity was found mainly in the supernatant fluid while the precipitate contained a stimulatory substance. The present paper reports on the activity of a few of these pineal fractions on rat uterine contractility induced in vitro by acetylcholine, pitocin and serotonin. Melatonin inhibited serotonin-induced rat uterine contractions (Hertz-Eshel \& Rahamimoff, 1965) as well as pitocin-induced uterine contractions of women and mice (Davis, McGowan \& Uroskie, in preparation). Oxytocic activity was isolated from bovine pineal gland (Milcu, Pavel \& Neacsu, 1963). The effect of pineal amines on various types of mammalian smooth muscle has received consideration (Wurtman, Axelrod \& Kelly, 1968).

Uteri from adult Sprague Dawley rats $(250 \mathrm{~g})$ were suspended in $30 \mathrm{ml}$ aerated de Jalon solution at $29.5^{\circ} \mathrm{C}$ and a single uterine contraction was induced by administering either one of three standards: $2 \mu \mathrm{g}$ acetylcholine, $10 \mathrm{mu}$ pitocin or $2 \mu \mathrm{g}$ of serotonin. The pineal extract was given in combination with the standard between two standard-induced contractions. The freezedried bovine pineal powders used were: TCA extract (Dowex, pH 7.4); supernatant of the original boiled residue from a simple aqueous extract; aqueous supernatant in a dialysing bag.

Study 1 (Text-fig. 1). Trichloroacetic acid extract $(0.1,0.5$ or $1.0 \mathrm{mg})$ was injected into the muscle bath simultaneously with serotonin $(2 \mu \mathrm{g})$ or pitocin $(10 \mathrm{mu})$ and exposed to the uterine horn for $3 \mathrm{~min}$. For comparison, serotonin or pitocin was injected before and after the double injection. The bath was washed out with $300 \mathrm{ml}$ of solution. The differences in contraction height $(\mathrm{mm})$ were expressed as \% change $(+=$ stimulation; $-=$ inhibition) above or below the standard. The standard error of the mean was obtained from six uteri per dose level.

Study 2 (Text-fig. 2). The supernatant of the original boiled pineal residue and the aqueous supernatant in the dialysing bag $(0.5$ to $10 \mathrm{mg}$ dose range) were each injected with $2 \mu \mathrm{g}$ acetylcholine. Exposure time was $5 \mathrm{~min}$. The height 


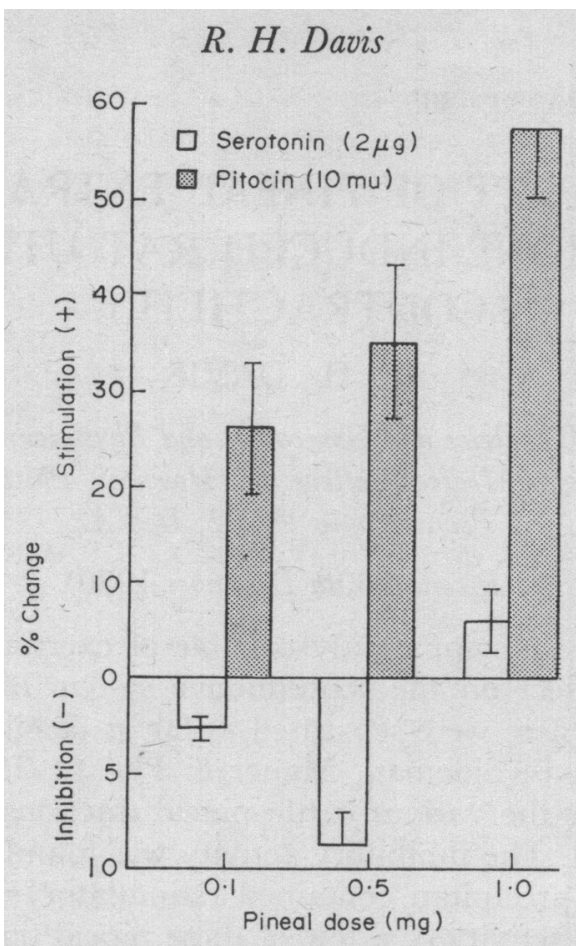

Text-Fic. 1. Percentage change above or below serotonin- or pitocin-induced rat uterine contractions by a pineal TCA extract. Bars at top of columns denote S.E.M. + = stimulation; $-=$ inhibition.

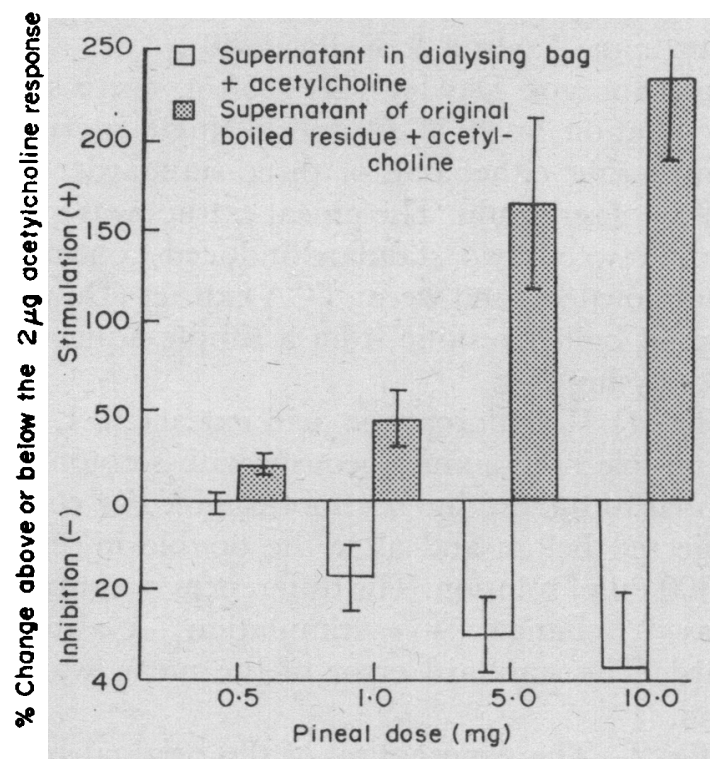

TExT-Fic. 2. Percentage change produced by the pineal fractions on $2 \mu g$ acetylcholineinduced rat uterine contractions. Bars at top of column denote S.E.M. + = stimulation; $-=$ inhibition. 
of contraction in $\mathrm{mm}$ was compared with the average acetylcholine-induced contraction height. The difference ( + or - ) was expressed as \% change above or below the acetylcholine response. The mean standard error was estimated from five to six uteri per dose.

Pineal stimulatory and inhibitory activity was demonstrated on hormoneinduced rat uterine contraction. Pineal extract, made by the TCA extraction procedure and purified through the Dowex column, increased the stimulatory effect of pitocin $57.2 \%$ at the highest dose level but had little or no influence on the stimulatory serotonin (Text-fig. 1). Text-figure 2 shows that a boiled aqueous extract of the original residue increased the $2 \mu \mathrm{g}$ acetylcholine-induced contraction from 19.6 to $233.3 \%$ in a dose-response fashion. A complete reverse effect was observed by the aqueous supernatant in the dialysing bag over the same dose range.

\section{REFERENGES}

Hertz-Eshel, M. \& Rahamimoff, R. (1965) Effect of melatonin on uterine contractility. Life Sci. 4, 1367.

Milcu, S. M., Pavel, S. \& Neacsu, C. (1963) Biological and chromatographic characterization of a polypeptide with pressor and oxytocic activities isolated from bovine pineal gland. Endocrinology, 72, 563.

Reiss, M., Davis, R. H., Sideman, M. B., Maugr, I. \& Plichta, E. S. (1963) Action of pineal extract on the gonads and their function. F. Endocr. 27, 107.

Wurtman, R. J., Axelrod, J. \& Kelly, D. E. (1968) The pineal gland, p. 77. Academic Press, New York. 